\title{
Numerical validation of Multiplex Acceleration Model for earthquake induced landslides
}

\author{
Lu Zheng*, Guangqi Chen, Kouki Zen and Kiyonobu Kasama \\ Department of Civil and Structural Engineering, Kyushu University, Fukuoka, Japan
}

(Received June 19, 2011, Revised November 23, 2011, Accepted January 2, 2012)

\begin{abstract}
Due to strong ground motion of earthquake, the material in the landslide can travel a significant distance from the source. A new landslide model called Multiplex Acceleration Model (MAM) has been proposed to interpret the mechanism of long run-out movement of this type of landslide, considering earthquake behaviors on slope and landslide materials. In previous study, this model was verified by a shaking table test. However, there is a scale limitation of shaking table test to investigate MAM in detail. Thus, numerical simulation was carried out in this study to validate MAM under full scale. A huge rock ejected and A truck threw upwards by seismic force during Wenchuan Earthquake (Ms. 8.0) was discussed based on the simulation results. The results indicate that collisions in P-phase of earthquake and trampoline effect are important behaviors to interpret the mechanism of long run-out and high velocity. The results show that MAM is acceptable and applicable.
\end{abstract}

Keywords: long run-out landslides; earthquake; Multiplex Acceleration Model; trampoline effect; UDEC.

\section{Introduction}

Landslide is frequent major hazard in mountainous areas, potentially serious threat in both property and life. It is important to estimate the run-out distance of landslide for disaster mitigation. In Japan, the "Law concerning disaster prevention due to landslide has been promulgated and adopted by the government since 2003 (cited by Chen et al. 2010). The Dangerous Area for a potential landslide is identified as 2 times of slope height but less than $50 \mathrm{~m}$ in this law (Fig. 1). It is established based on statistics of the run-out distances in historical events, which were mainly triggered by heavy-rains.

However, during the last 15 years, after a series of catastrophic earthquake events in Japan (1995), Taiwan (1999), El Salvador (2001), Pakistan (2005) and China (2008), increasing attention has been addressed to landslides triggered by earthquakes.

Due to the strong ground motion of earthquake, the landslide can travel a distance several times longer than the height of the slope at a high velocity and result in great damages and losses (Keefer 1984, Sassa 1996, Rodriguez et al. 1999, Keefer 2002, Bird and Bommer 2004, Havenith and Bourdeau 2010). For example, there were many landslides with run-out distances over $1000 \mathrm{~m}$ triggered by the 2008 Wenchuan Earthquake (Ms. 8.0). Fig. 2 shows a typical long run-out landslide

*Corresponding author, Ph.D., E-mail: lu.zheng8211@gmail.com 


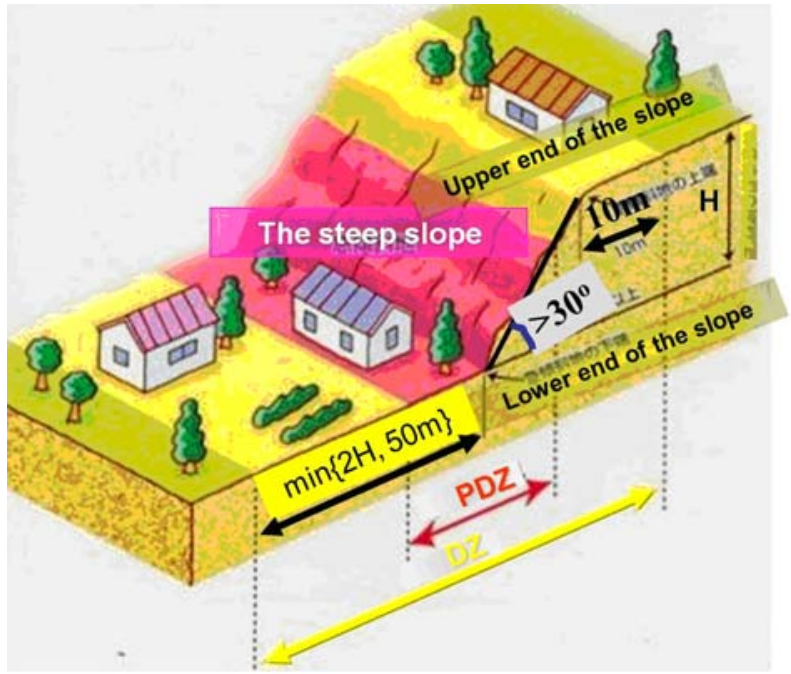

Fig. 1 The Dangerous Zone (DZ) for a potential landslide identified by law in Japan
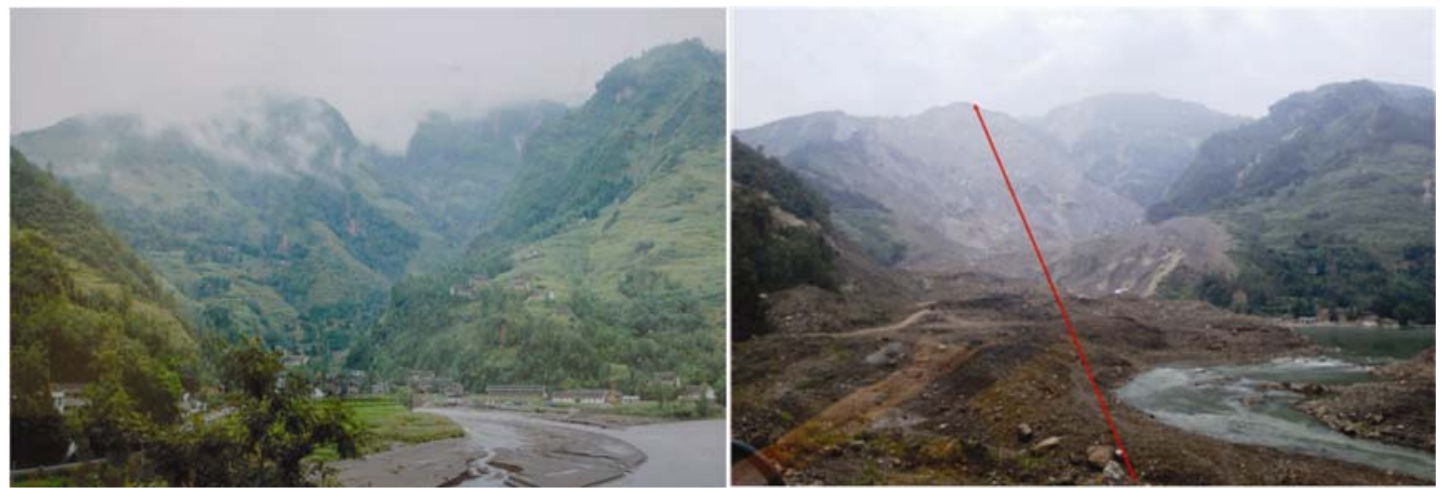

Fig. 2 The landslide induced by the 2008 Wenchuan Earthquake in Donghekou, Qingchuan prefecture, Sichuan province, China

induced in Donghekou, Qingchuan prefecture of Sichuan province, China. It traveled around 2800 $\mathrm{m}$ within $80 \mathrm{~s}$. It is obviously that the Dangerous Area should be much larger for earthquake induced landslides. Therefore, it is very important to investigate the mechanism of high speed \& long distance and predict its run-out zone.

Analyses performed according to the Newmark (1965) approach at regional scale allow developing different earthquake triggered landslide scenarios (Luzi and Pergalani 1996, Miles and Ho 1999, Romeo 2000, Chang et al. 2005, Mahdavifar et al. 2008). These sliding block models are based on the simplifying assumption that the sliding mass is rigid. Among its deficiencies: it provides limited information on the evolution of the landslide and does not reproduce the mechanisms of deposition of the slope material. On the other hand, elasto-plastic continuum models (Sassa 1996, Vardoulakis 2002, Troncone 2005) fully considered the deformability of the sliding mass are capable of simulating the formation and development of shear zones with realism, thereby leading to improved modeling failure mechanism. And if assuming the sliding mass behaves as a liquid mixture of fluids 
and solids, depth-integrated models can be used in modeling post-liquefaction behavior of granular soil induced by earthquake (Gerolymos 2010).

According to field investigation, the landslides in Wenchuan Earthquake could be illustrated by following characteristic: the debris mass was separately expanded and thrown under long-period strong ground vibration (Yin 2009). It can be interpreted that debris mass consist of rock fragments is not a continuum, its behavior due to presence of joint sets, bedding planes and faults etc. Moreover, some landslide sites are relatively dry. Thus, the current mechanisms and models such as Liquefaction (Sassa 1988), flow mechanism (Hungr 1995, Davies and McSaveney 2002) which are mainly continuum, flow like and concentrating on the loss of material strength, are not adapt for these cases. Then in order to interpret the long run-out mechanism of landslide triggered by earthquake and predict its run-out, we have presented a new model called "Multiplex Acceleration Model (MAM) base on consideration of the "trampoline effect during earthquake (Chen et al. 2010). Subsequently, this model tests were verified by a shaking table test investigating the effects of earthquake on the movement of debris. However, it is difficult to distinguish the velocity obtained from P-Phase of earthquake since the scale limitation.

The Discrete Element Method (DEM), originally proposed by Cundall (1971), is a totally discontinuum-based method specially designed to model jointed and fractured rock masses. In the distinct element method, rock mass is represented as an assembly of discrete bodies and fractures are considered as interfaces between distinct bodies. The blocks can be rigid or be deformable with FDM or FEM discretizations. Large displacements caused by rigid body motion of individual blocks, including block rotation, fracture opening and complete detachments is straightforward in the DEM. In geotechnical practice, it is a commonly used discrete element approach for investigating the kinematics of landslides. Using detail geological and geotechnical data, DEM or DDA can be used to interpret the post-failure movement of landslide masses in good agreement with filed investigation (e.g., Bhasin and Kaynia 2004, Wu et al. 2008, Tang et al. 2009).

In this paper, we have attempted to simulate the phenomenon of velocity of debris gained from the vibration of the slope and its further amplification during an earthquake using the Universal Distinct Element Code (UDEC) developed by Cundall (1980). The results can be used to verify the acceptability and applicability of MAM.

\section{Energy analysis in MAM}

In MAM, the vibration of a slope caused by earthquake wave can be divided into two phases: PPhase and N-Phase as shown in Fig. 3. The $P$-Phase is defined as the period when the slope is moving in the outer normal direction of the slope surface. The debris on the surface will be pushed and accelerated by the slope in this phase. The N-Phase is defined as the period when the slope is moving in the inner normal direction of the slope surface. Since slope surface moves apart from the debris, the friction should be declined.

The roles of the two phases can be seen more clearly by apparent friction angle analysis. Supposing that a stone with mass $m$ moves from position $A$ to position $B_{1}$ during a landslide without earthquake (Case 1), the potential energy decreases by $m g h_{1}$ Based on the energy conservation law, it is easy to obtain the following equation for a falling stone movement in the case without earthquake (see Case 2 in Fig. 4). 


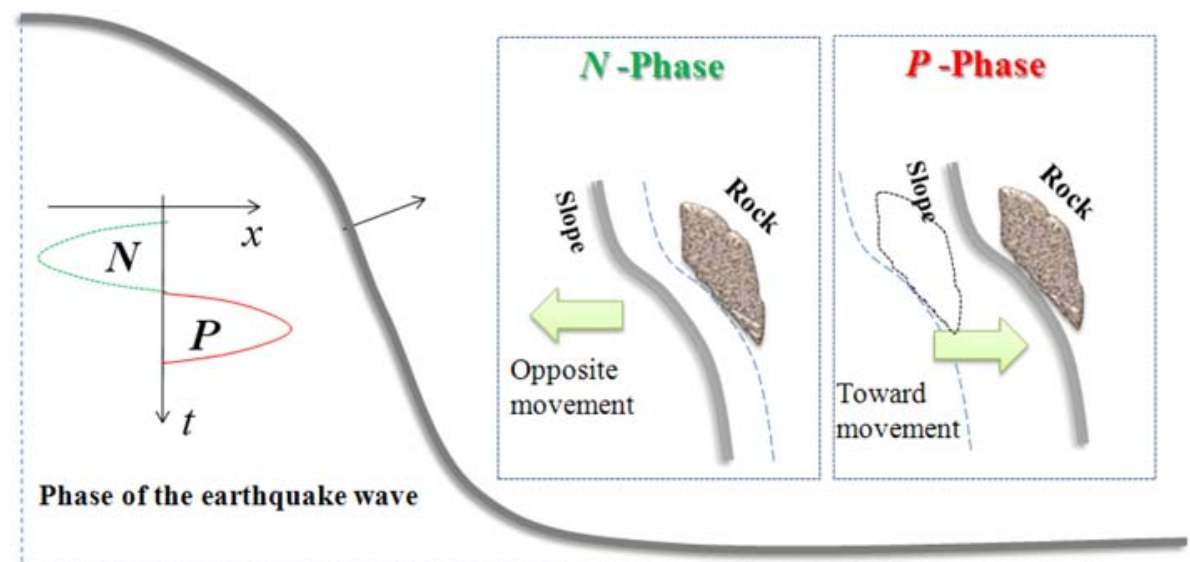

Fig. $3 P$-Phase and $N$-Phase of an earthquake wave

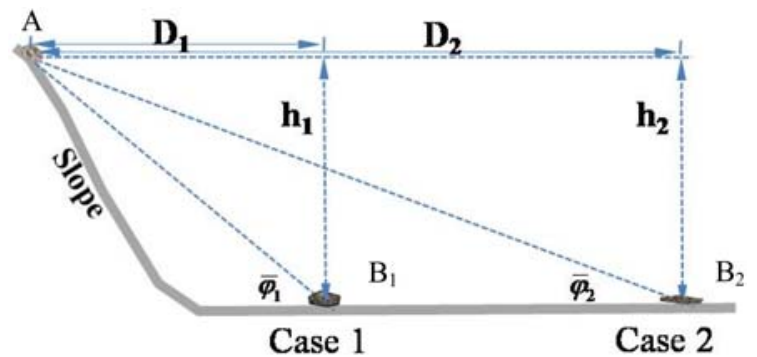

Fig. 4 Apparent friction angles of case without earthquake and case with earthquake

$$
m g h_{1}-\sum_{i} l_{i} m g k_{i} \tan \varphi_{s i} \cos \theta_{i}=0
$$

The first term here is for potential energy and the second item is for the work of friction force between the slope and the falling stone, where the sliding movement is considered and the whole curve path is divided into finite linear segments. And $m$ is the mass, $g$ is the gravity acceleration, $h_{1}$ is the falling height in the case without earthquake, $l$ is the segment length, $\theta$ is the segment slope angle, $\varphi$ is the friction angle, $k$ is the coefficient of conveying from static to dynamic friction and $i$ is the index of segment.

The apparent friction angle can be obtained from Eq. (1) as follows

$$
\begin{gathered}
\tan \bar{\varphi}_{1}=\frac{h_{1}}{D_{1}}=\sum_{i} w_{i} k_{i} \tan \varphi_{s i} \\
w_{i}=\frac{1}{D_{1}} l_{i} \cos \theta_{i}
\end{gathered}
$$

Where, $D_{1}$ is the run-out distance in the case without earthquake, $w$ is the parameter of slope segment geometry versus total run-out distance.

The apparent friction angle expressed in Eq. (2) is usually used for the discussion of run-out distance of landslide. 
When we consider the effects of slope vibration due to earthquake (mass moves to $\mathrm{B} / 2$ ), the kinetic energy of falling stone obtained from the collision with the vibrating slope and the movement patterns (sliding, rolling and flying) should be considered. Thus, Eq. (1) becomes

$$
m g h_{2}+\sum_{i} \frac{1}{2} m v_{e j}^{2}-\sum_{i} l_{i} m g k_{i}^{*} \tan \varphi_{s i} \cos \theta_{i}=0
$$

Where, $h_{2}$ is the falling height in the case with earthquake. The second item here is for the kinetic energy of a falling stone obtained from the collision with the vibrating slope and $v_{e j}$ is the velocity obtained in $j^{\text {th }} \mathrm{P}$-Phase and can be expressed as follows

$$
v_{e j}=V T R \int_{t_{i}}^{t_{i}+\Delta t} f(t) d t
$$

$f(t)$ is the acceleration of slope vibration due to earthquake, $V T R$ is called the velocity transmission ratio due to collision.

The apparent friction angle for the Case 2 in Fig. 4 can be obtained from Eq. (3) as follows

$$
\tan \bar{\varphi}_{2}=\frac{h_{2}}{D_{2}}=\sum_{i} w_{i} k_{i}^{*} \tan \varphi_{s i}-\frac{1}{2 g D_{2}} \sum_{i} v_{e j}^{2}
$$

Where, $D_{2}$ is the run-out distance in the case with earthquake. Comparing Eq. (5) with Eq. (2), it can be found that:

The kinetic energy of a falling stone obtained from the collision with the vibrating slope may result in long run-out distance from the second item of Eq. (5).

The coefficient of conveying from static to dynamic friction $k^{*}$ in Eq. (5) can be smaller than $k$ in Eq. (3) because of the $N$-Phase effect, air cushion effect, movement pattern.

\section{Verification with respect to analytical solution}

Before applying the MAM to field cases, it dictates examining a set of simple models to verify and validate it. In P-Phase, a falling stone can obtain kinetic energy from the colliding with the vibrating slope. According to elastic collision theory, when two objects with different masses collide with each other, the object with smaller mass could obtain larger velocity. Since the mass of a slope is much larger than the mass of a falling stone, the velocity of the falling stone can be much larger than the vibrating velocity of the slope. That is to say the VTR in Eq. (6) can be larger than 1.

$$
V T R=\frac{V_{21}}{V_{10}}
$$

The VTR can be examined by the simple model shown in Fig. 5. The masses of the two blocks are $m_{1}$ and $m_{2}$ respectively. Before the colliding, the block 1 has initial velocity $V_{10}$ toward block 2 which is standstill, i.e., $V_{20}=0$. The friction between blocks and the base is negligible. After the colliding, the velocity of block 1 becomes $V_{11}$ while block 2 obtains a velocity $V_{21}$.

According to the principles of the conservation of both energy and momentum, we have the following equations. 


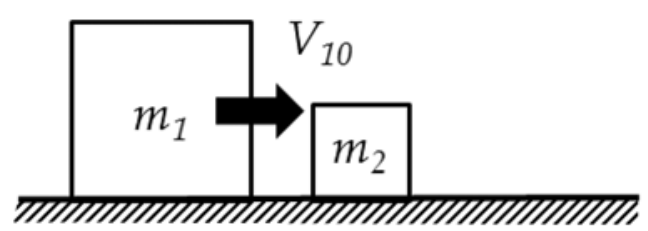

(a) Before colliding

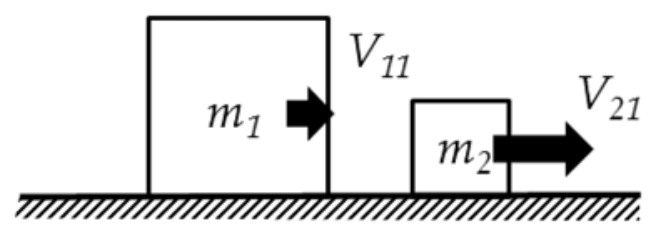

(b) After colliding

Fig. 5 Colliding model: (a) Before the collision and (b) After the collision

Table 1 Parameters used in UDEC simulations for colliding model

\begin{tabular}{lc}
\hline \hline Parameters & Value \\
\hline Density $\left(\mathrm{kg} / \mathrm{m}^{3}\right)$ & $2.00 \times 10^{3}$ \\
Bulk Modulus $(\mathrm{MPa})$ & $2.78 \times 10^{3}$ \\
Shear Modulus $(\mathrm{MPa})$ & $2.08 \times 10^{3}$ \\
Contact stiffness $(\mathrm{KN} / \mathrm{m})$ & $1.00 \times 10^{6}$ \\
\hline
\end{tabular}

$$
\begin{aligned}
\frac{1}{2} m_{1} V_{10}^{2}+\frac{1}{2} m_{2} V_{20}^{2} & =\frac{1}{2} m_{1} V_{11}^{2}+\frac{1}{2} m_{2} V_{21}^{2} \\
m_{1} V_{10}+m_{2} V_{20} & =m_{1} V_{11}+m_{2} V_{21}
\end{aligned}
$$

By solving Eq. (7) and Eq. (8), we can obtain the VTR for the case of $V_{20}=0$ as follows

$$
V T R=\frac{2 m_{1}}{m_{1}+m_{2}}
$$

It can be seen from the analytical solution Eq. (9) that if $m_{1}$ is much larger than $m_{2}$,VTR is approaching to 2 . Therefore, since the mass of a slope is far larger than the falling stone, the velocity of the falling stone obtained from the slope vibration will be two times of that of the slope vibration velocity during earthquake.

The results of VTR given in analytical solution Eq. (9) have been verified by UDEC simulation. The model shown in Fig. 5 and the parameters given in Table 1 are used in UDEC simulations. The results obtained from UDEC simulations by changing $m_{1}$ are shown in Fig. 6, together with the theoretical analytical values. The line is calculated from the analytical solution Eq. (9) and the dots are obtained from UDEC simulations. It can be seen that the VTR obtained from UDEC is in quite good agreement with the analytical solution.

Furthermore, if the block 2 has an initial velocity toward block 1, the VTR could become larger 

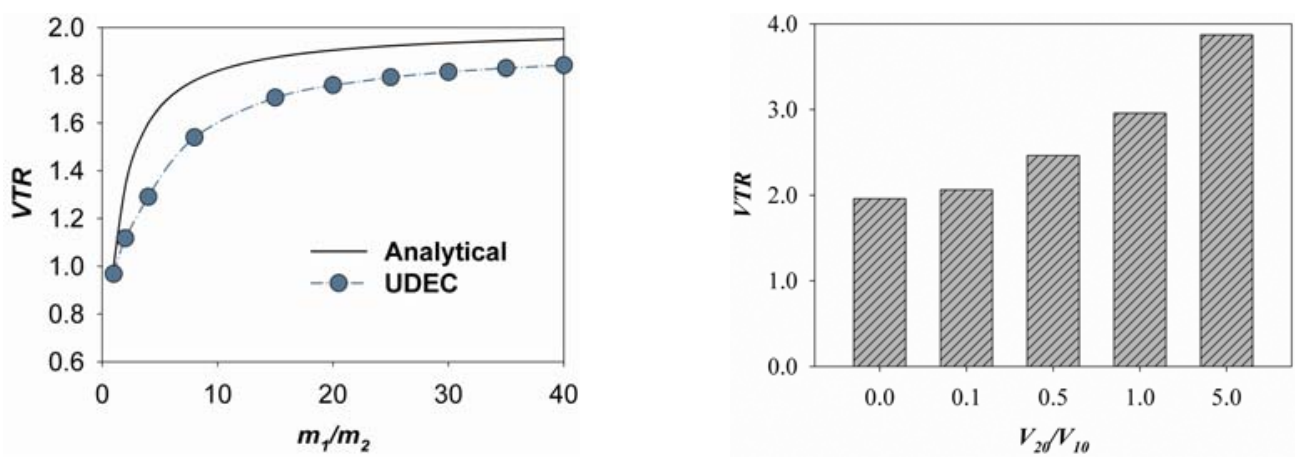

Fig. 6 The VTR obtained by both the analytical Fig. 7 The VTR varied with the initial velocity of solution and UDEC simulation block 2: trampoline effect

and larger. Fig. 7 shows the results from UDEC simulation. It seems that a trampoline effect can be produced by strong earthquake.

It should be pointed out that the results do not change when the mass and the initial velocity of block one are different from the values in Table 1. That is to say, the result given in Fig. 6 has the general meaning.

\section{Verification with respect to field data}

\subsection{Rock ejected by seismic wave}

During Wenchuan Earthquake, in the epicenter area, a rock of 300 tons traveled a horizontal distance about $58 \mathrm{~m}$ from the slope at the height about $71.5 \mathrm{~m}$ as shown in Fig. 8. Since it finally inserted into ground and its shape made it difficult to rotate and stand, it was judged as an ejecting and flying movement.

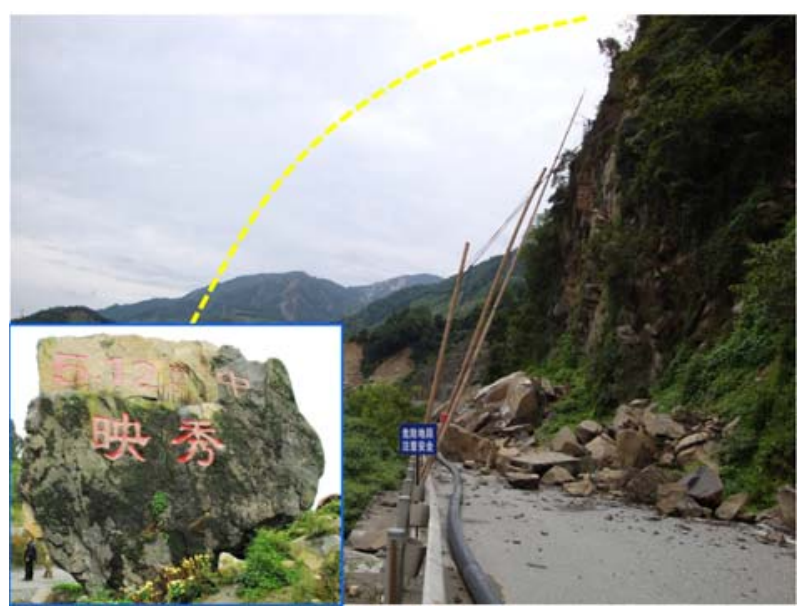

Fig. 8 A 300 tons rock ejected in epicenter area 


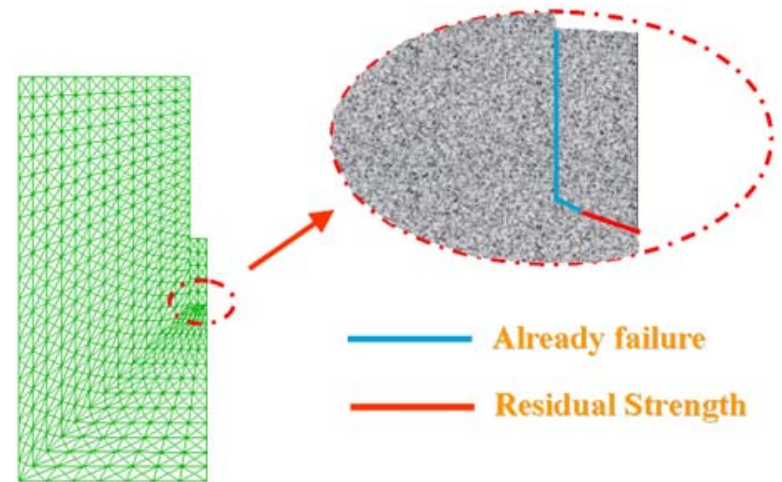

Fig. 9 UDEC mesh of ejected rock phenomenon (horizontal view)

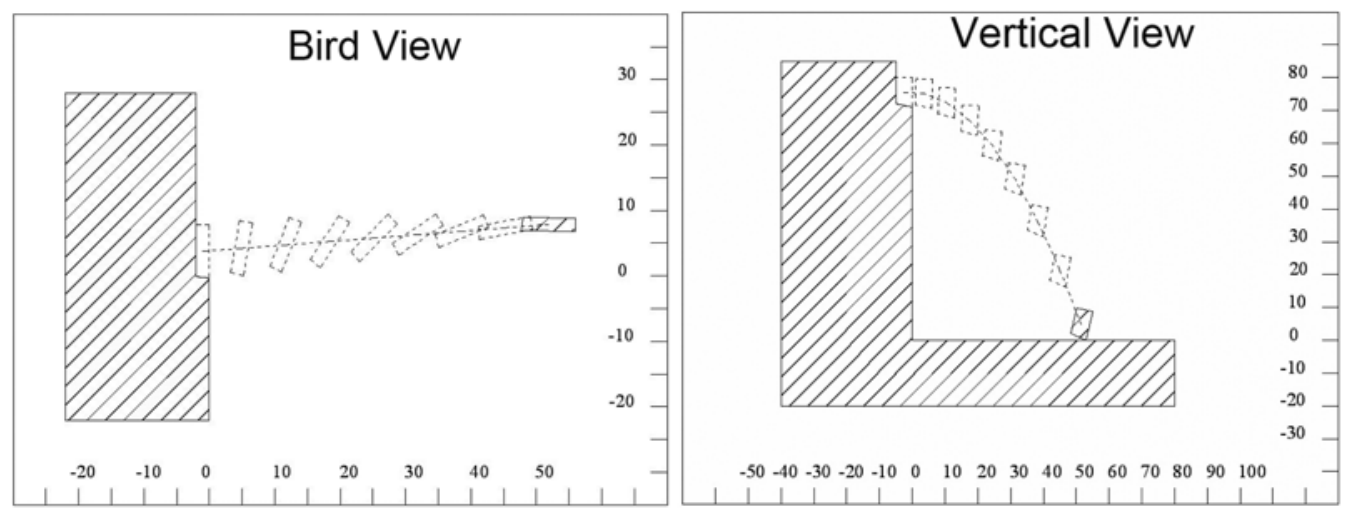

Fig. 10 UDEC simulation results with $P G A 3000$ gal

Consequently, with the energy conservation in ejection, the ejection distance as a function of height $h$ along vertical direction

$$
t=\sqrt{\frac{2 h}{g}}=3.82 \mathrm{~s}
$$

And the necessary horizontal velocity can be calculated out from the horizontal distance $d$

$$
v_{h}=\frac{d}{t}=15.2 \mathrm{~m} / \mathrm{s}
$$

$\mathrm{Xu}$ and Huang (2008) used a constant acceleration with a period $1.25 \mathrm{~s}$ that it found the $P G A$ could be estimated as

$$
a=\frac{v_{h}}{t_{c p}}=1216 \mathrm{gal}
$$

Where, $t_{c p}$ means the period of the constant acceleration.

However, constant acceleration is rare during earthquake.

The UDEC model is shown in Fig. 9. The part of joint was supposed to have residual strength. 


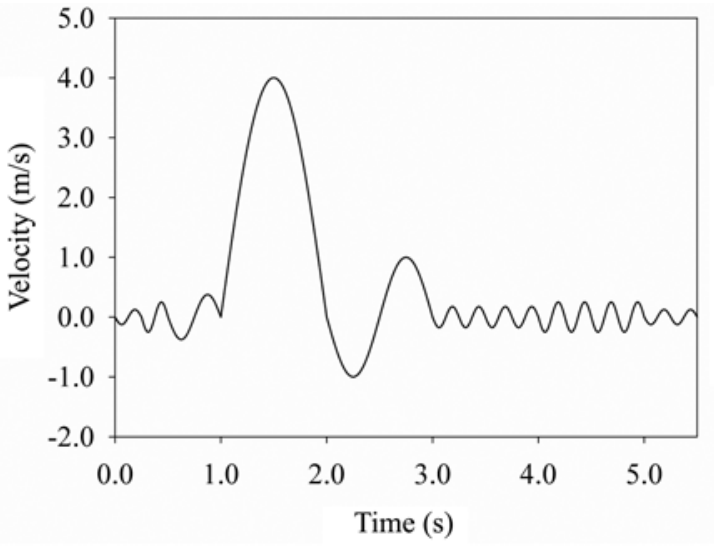

(a)

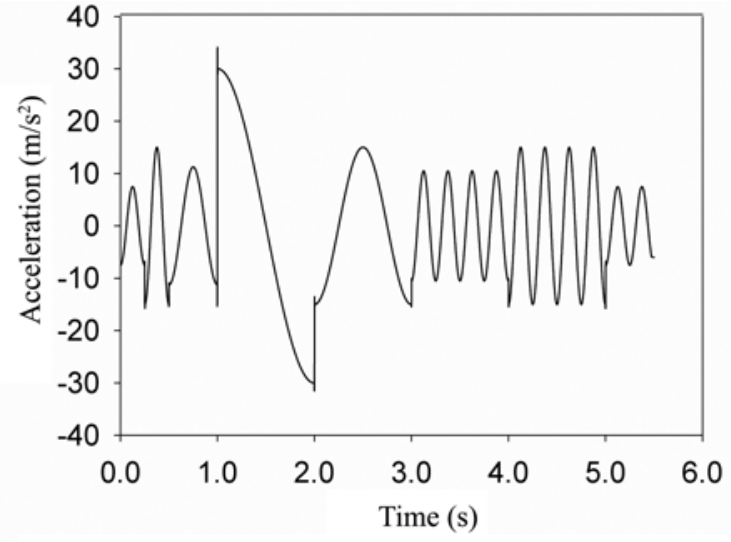

(b)

Fig. 11 Input seismic wave for rock ejected: (a) Input velocity wave which consists of several harmonic waves, (b) Output acceleration wave for validation: $P G A=3000$ gal

Table 2 Physico-mechanical parameters for rock ejected

\begin{tabular}{lc}
\hline \hline Parameters & Value \\
\hline Density $\left(\mathrm{kg} / \mathrm{m}^{3}\right)$ & $2.50 \times 10^{3}$ \\
Bulk Modulus $(\mathrm{MPa})$ & $2.78 \times 10^{3}$ \\
Shear Modulus $(\mathrm{MPa})$ & $2.08 \times 10^{3}$ \\
\hline
\end{tabular}

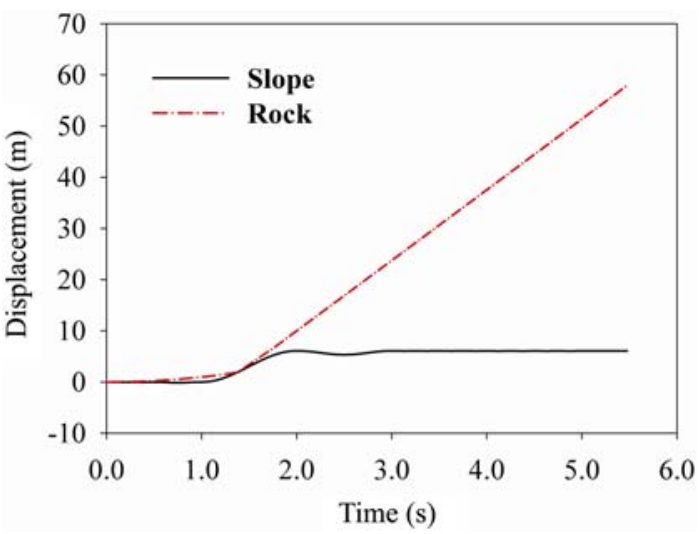

Fig. 12 Displacement versus time for rock ejected
Table 3 Mechanical parameters of joint for rock ejected

\begin{tabular}{lcc}
\hline \hline Parameters & $\mathrm{a}$ & $\mathrm{b}$ \\
\hline $\mathrm{Kn}(\mathrm{KN} / \mathrm{m})$ & $5.00 \times 10^{6}$ & $5.00 \times 10^{6}$ \\
$\mathrm{Ks}(\mathrm{KN} / \mathrm{m})$ & $5.00 \times 10^{6}$ & $5.00 \times 10^{6}$ \\
Tension $(\mathrm{MPa})$ & 0.0 & $1.70 \times 10^{1}$ \\
Cohesion $(\mathrm{MPa})$ & 0.0 & $1.70 \times 10^{1}$ \\
Friction Angle $\left(^{\circ}\right)$ & 45.0 & 45.0 \\
\hline
\end{tabular}

a: joints between totally developed and already failure; b: joints between with residual strength;

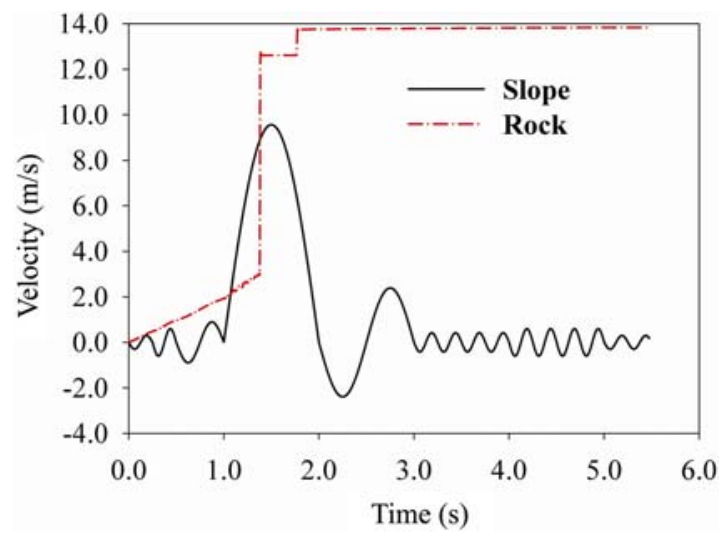

Fig. 13 Velocity versus time for rock ejected

Since, the limited area was considered as an approximately rigid one, the earthquake acceleration was added after turning into velocity wave on all the mesh vertices of the slope. In Fig. 10, an earthquake wave consists of several harmonic waves with different frequency could be used to 


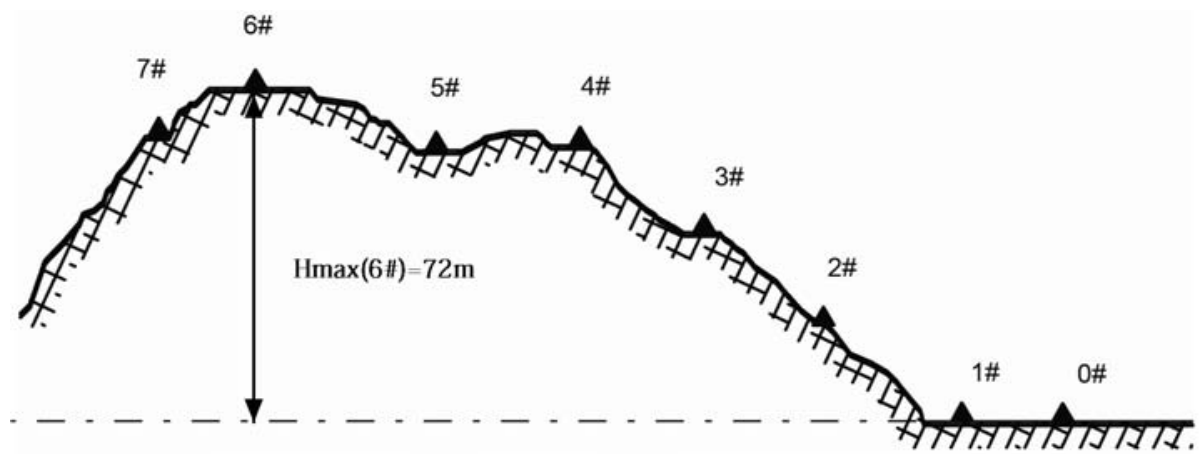

(a)

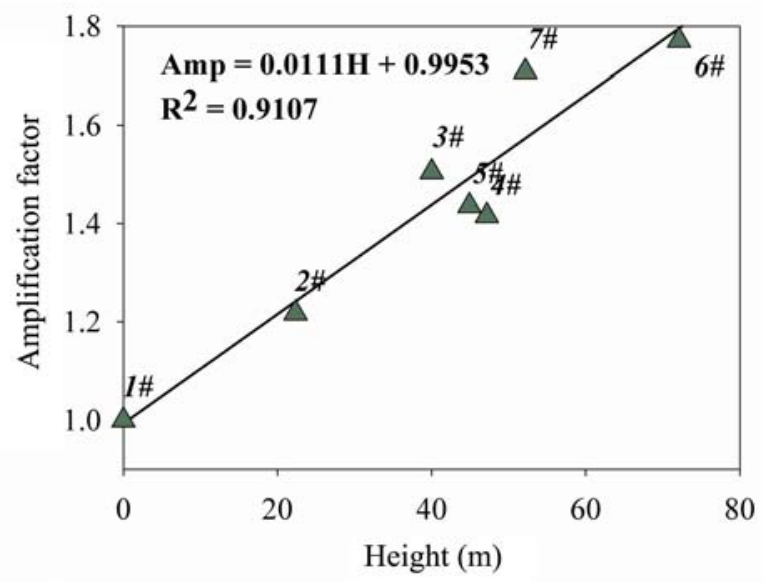

(b)

Fig. 14 Topographic amplification effect at Zigong topographic array: (a) Zigong topographic array, (b) Topographic amplification effect by height

represent this phenomenon. The input velocity wave in UDEC is shown Fig. 11(a). And the acceleration wave was outputted for validation as shown in Fig. 11(b). The PGA was 3000 gal in this case. The parameters are listed in Table 2 and Table 3. After the simulation, the displacements of slope and rock are shown in Fig. 12. It shows two collides occurred. The velocities of both slope and rock are shown in Fig. 13. The comparison result shows the colliding effect in one $P$-Phase gives the rock a large initial velocity. And the VTR is 1.46.

Links between surface geometry and local geology, amplifications of acieration have been reported by many researchers. There is also amplification effect during the Wenchuan Earthquake, reported by data from the Zigong topographic array (Wang and Xie 2010), shown in Fig. 14. The horizontal $P G A$ had an amplification factor about 1.8 at the height of $70 \mathrm{~m}$. Thus, considering that a $P G A$ of 1500 gal was recorded at a strong motion station in Zipingpu dam region, the ground motion parameter back calculated by MAM is reasonable.

It is important to point out that, if without the collision effect represented by MAM, the acceleration should be more than 5000 gal that is impossible even in the Wenchuan Earthquake (Ms. 8.0). 


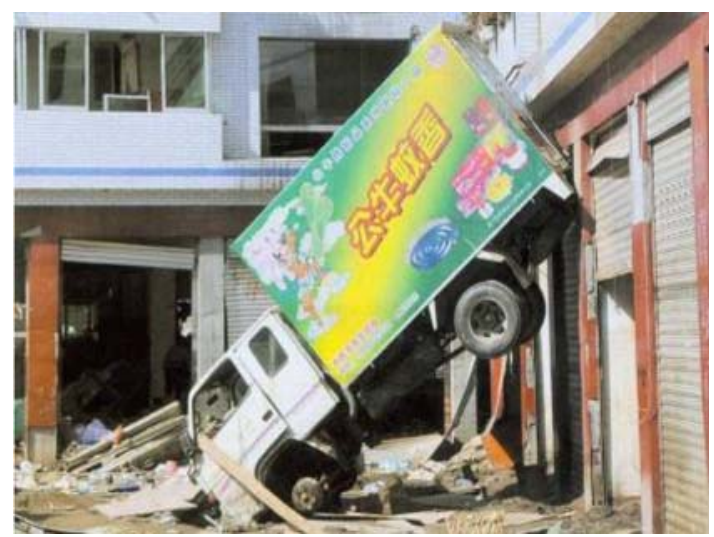

Fig. 15 Truck threw up by vertical seismic wave

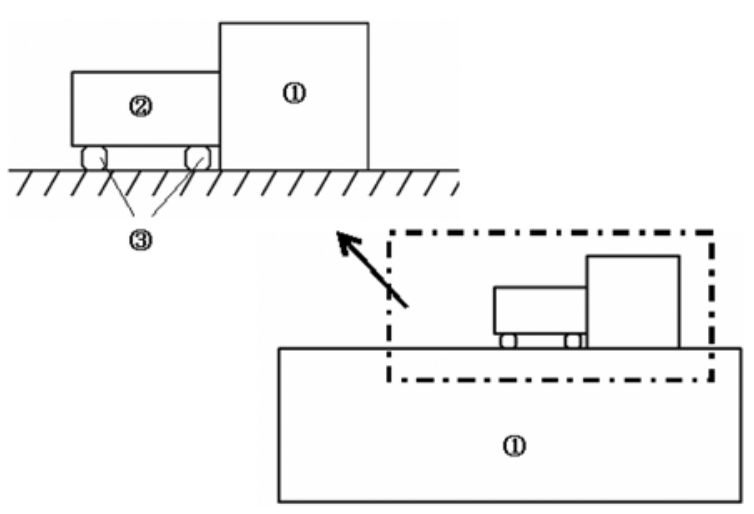

Fig. 16 UDEC model of truck threw up

Table 4 Physico-mechanical parameters for truck threw up

\begin{tabular}{lccc}
\hline \hline Parameters & (1) & $(2)$ & $(3)$ \\
\hline Density $\left(\mathrm{kg} / \mathrm{m}^{3}\right)$ & $2.00 \times 10^{3}$ & $3.00 \times 10^{3}$ & $2.00 \times 10^{3}$ \\
Bulk Modulus $(\mathrm{MPa})$ & $2.78 \times 10^{3}$ & $2.78 \times 10^{3}$ & $2.78 \times 10^{1}$ \\
Shear Modulus $(\mathrm{MPa})$ & $2.08 \times 10^{3}$ & $2.08 \times 10^{3}$ & $2.08 \times 10^{1}$ \\
\hline
\end{tabular}

(1): house and base ground; (2): truck body; (3): wheel;

Table 5 Mechanical parameters of joint for truck threw up

\begin{tabular}{lcc}
\hline \hline Parameters & $\mathrm{a}$ & $\mathrm{b}$ \\
\hline $\mathrm{Kn}(\mathrm{KN} / \mathrm{m})$ & $5.0 \times 10^{6}$ & $5.00 \times 10^{6}$ \\
$\mathrm{Ks}(\mathrm{KN} / \mathrm{m})$ & $5.0 \times 10^{6}$ & $5.00 \times 10^{6}$ \\
Tension $(\mathrm{MPa})$ & 0.0 & $1.00 \times 10^{4}$ \\
Cohesion $(\mathrm{MPa})$ & 0.0 & $1.00 \times 10^{4}$ \\
Friction Angle $\left({ }^{\circ}\right)$ & 30.0 & 70.0 \\
\hline
\end{tabular}

a: joints between wheels and baseground;

b: joints between wheels and truck, house and baseground;

\subsection{Truck threw up by vertical seismic wave}

In the 2008 Wenchuan Earthquake (Ms. 8.0), the records of acceleration showed that very large $P G A$. In some place, the vertical $P G A$ was even bigger than horizontal $P G A$. Fig. 15 shows a truck was found leaning against the wall after earthquake. It indicated a strong vertical seismic wave caused this phenomenon. Fig. 16 is a simple model used to simulate it. The parameters are listed in Table 4 and Table 5. A joint with strong Cohesion, Tension value and large friction angle was used to fix the house on the base land and wheels on truck. Fig. 17 is the mesh generated in UDEC.

Since: (1). there is no earthquake record station nearby the study area; (2). earthquake wave is largely affected by geology, topography et al., the real earthquake curves in this area are not available and the recorded waves are not suitable to use. However, the $P G A$ can be used to present the earthquake strength. So a simple harmonic wave as part of earthquake with the same $P G A$ was 


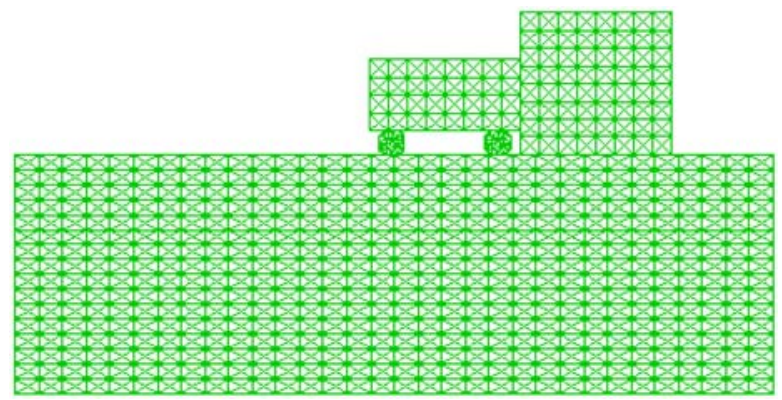

Fig. 17 UDEC mesh of truck threw up

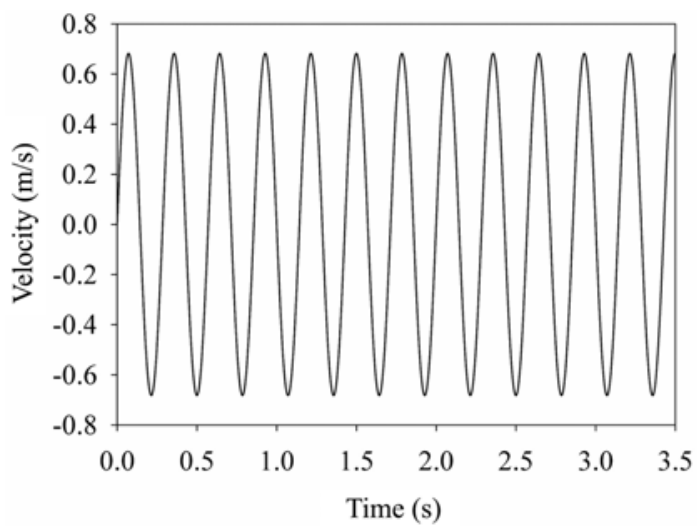

(a)

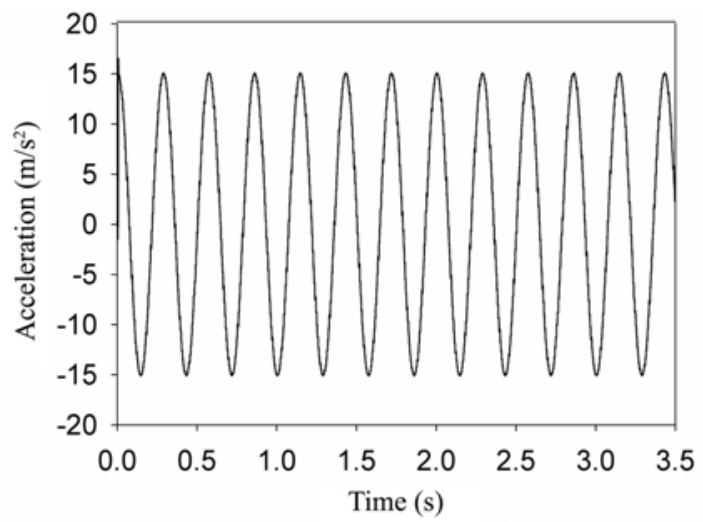

(b)

Fig. 18 Input seismic wave for truck threw up: (a) Input velocity wave which consists of several harmonic waves, (b) Output acceleration wave for validation: $P G A=1500 \mathrm{gal}$

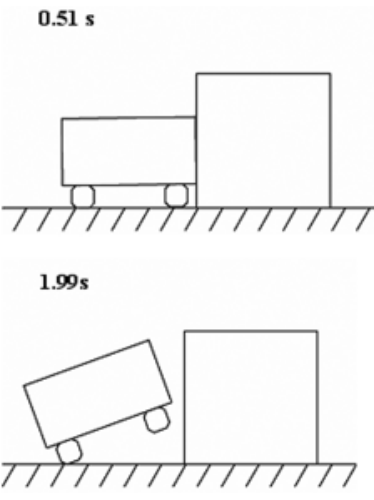

$1.13 \mathrm{~s}$

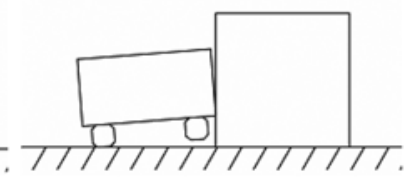

$3.50 \mathrm{~s}$

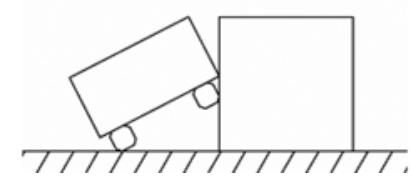

Fig. 19 Truck threw up process by UDEC simulation

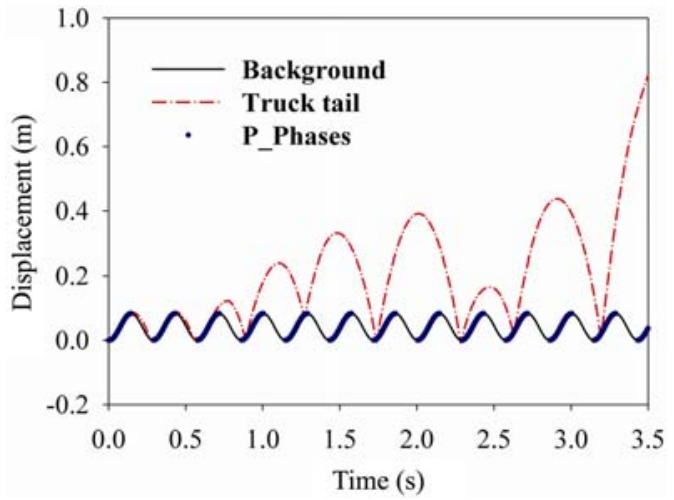

Fig. 20 Displacement versus time for truck threw up

used to simulate the phenomenon in order to qualitatively analysis the mechanism firstly. In this study, a sine wave of velocity, which was turned into stress wave, was added on all the mesh vertices of background. The wave presented PGA 1500 gal, Frequency $3.5 \mathrm{~Hz}$, according to that there was a $P G A=1500$ gal recorded at a strong motion station in Zipingpu dam region. Considering 


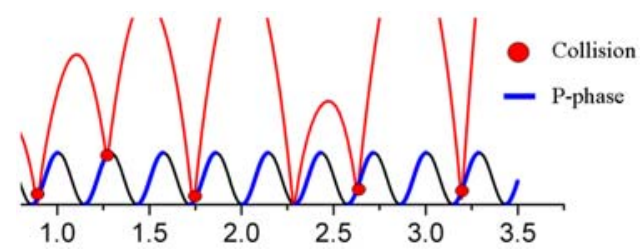

Fig. 21 Collisions in $P$-Phases

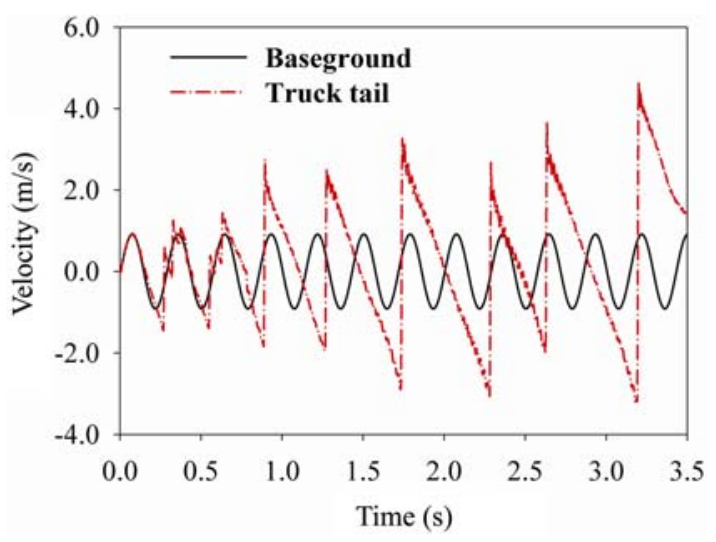

Fig. 22 Velocity versus time for truck threw up

this model is limited near the ground surface and neglecting the effect of wave propagation, the base ground was treated as vibrating like a whole one and the earthquake acceleration was added on all the mesh vertices after turning into velocity wave as shown in Fig. 18.

The movements of truck at different times obtained from UDEC simulation are shown in Fig. 19. The rotation displacement is very small at very beginning. But following results show that the truck was threw up higher and higher with time passing by the trampoline effect of vertical seismic wave.

Fig. 20 is the results of displacement vs. time. Black line is the displacement in base. Blue part of base displacement shows the $P$-Phases in which base moved upward to the truck. Red line is the displacement at the tail of truck. The intersection points of two lines indicate the collisions. Fig. 21 clearly shows that almost all the intersection points located at the blue part. That means collisions threw the truck up which almost happened at the $P$-Phases. It also indicates that if there are continuous collisions in $P$-Phases, the collision effect would turn to a trampoline movement.

Fig. 22 shows the results of velocity vs. time. Black line is the velocity in base. Red line is the velocity at the tail of truck. It clearly shows that during the vibration of base ground, trampoline effect happened.

\section{Conclusions}

A rock ejected and a car threw upwards was simulated by UDEC. The simulations reproduced the whole process reasonably compared to the field data. The least GPA could be estimated as $3.0 \mathrm{~g}$ on the top surface of the slope in the epicenter area based on the simulation of the ejected rock near Yingxiu town.

The verification studies, presented here, illustrate the important behavior of Multiplex Acceleration Model to interpret the mechanism of high-speed and long run-out landslide with respect to both analytical solution and filed data. Specifically,

Collision effects at $P$-Phase can be an important factor which would cause high-speed and long run-out landslide;

Further, it will turn to trampoline effect which will make the intensity grow up.

The results indicate it is acceptable and applicable to use Multiplex Acceleration Model to 
analysis earthquake induced landslide disasters.

\section{Acknowledgements}

This study have received financial support from the Global Environment Research Found of Japan (S-8), and from Grants-in-Aid for Scientific Research (Scientific Research (B), 22310113, G. Chen) from Japan Society for the Promotion of Science. These financial supports are gratefully acknowledged.

\section{References}

Bhasin, R. and Kaynia, M.A. (2004), "Static and dynamic simulation of a 700-m high rock slope in western Norway", Eng. Geol., 71(3-4), 213-226.

Bird, J.F. and Bommer, J.J. (2004), "Earthquake losses due to ground failure", Eng. Geol., 75(2), 147-179.

Chang, K.J., Taboada, A., Lin, M.L. and Chen, R.F. (2005), "Analysis of landsliding by earthquake shaking using a block on slope thermo-mechanical model: Example of Jiufengershan landslide", central Taiwan. Eng. Geol., 80(1-2), 151-163.

Chen, G.Q., Zen, K., Zheng, L. and Jiang, Z.S. (2010), "A new model for long-distance movement of earthquake induced landslide", Proceedings of the 44th U.S. Symposium on Rock Mechanics, Salt Lake City, UT, USA.

Cundall, P.A. (1971), "A computer model for simulating progressive large scale movements in blocky rock systems", Proceedings of the Symposium of the International Society of Rock Mechanics, Nancy, France.

Cundall, P.A. (1980), UDEC - A Generalized Distinct Element Program for Modeling Jointed Rock, Peter Cundall Associates, Report PCAR-1-80, U.S. Army, European research Office, London.

Davies, T.R. and McSaveney, M.J. (2002), "Dynamic simulation of the motion of fragmenting rock avalanches", Canadian Geotechnical Journal, 39(4), 789-798.

Gerolymos, N. (2010), Numerical modeling of seismic triggering, evolution and deposition of rapid landslides: Application to Higashi-Takezawa (2004), Int. J. Numer. Anal. Meth. Geomech., 34(4), 383-407.

Havenith, H. and Bourdeau, C. (2010), "Earthquake-induced landslide hazards in mountain regions: A review of case histories from central Asia", Geol. Bel., 13(3), 137-152.

Hungr, O. (1995), "A model for the runout analysis of rapid flow slides, debris flows, and avalanches", $J$. Geotech. Eng., 32(4), 610-623.

Itasca Consulting Group, Inc. (2004), UDEC-Universal distinct element code, Version 4.0 Manual, Itasca Consulting Group, Inc., Minneapolis.

Keefer, D.K. (1984), "Landslides caused by earthquakes", Geol. Soc. Am. Bull., 95(4), 406-421.

Keefer, D.K. (2002), "Investigating landslides caused by earthquakes - A historical review", Surv. Geophys., 23(6), 473-510.

Luzi, L. and Pergalani, F. (1996), "Application of statistical and GIS techniques to slope instability zonation (1:50,000 Fabriano geological map sheet)”, Soil. Dyn. Earthq. Eng., 15(2), 83-94.

Mahdavifar, M., Jafari, M.K. and Zolfaghari, M.R. (2008), "GIS-based real time prediction of Arias intensity and earthquake-induced landslide hazards in Alborz and Central Iran", Landslides and engineered slopes. Taylor and Francis Group, London. ISBN: 978-0-415-41196-7:1427-1438.

Miles, S.B. and Ho, C.L. (1999), "Rigorous landslide hazard zonation using Newmark's method and stochastic ground motion simulation", Soil. Dyn. Earthq. Eng., 18(4), 305-323.

Newmark, N.M. (1965), "Effects of earthquakes on dams and embankments", Geotechnique, 15, 139-159.

Rodriguez, C.E., Bommer, J.J. and Chandler, R.J. (1999), "Earthquake-induced landslides: 1980-1997, Soil", Dyn. Earthq. Eng., 18(5), 325-346.

Romeo, R. (2000), "Seismically induced landslide displacements: a predictive model", Eng. Geol., 58(3/4), 337351.

Sassa, K. (1988), "Geotechnical model for the motion of landslides", Special Lecture of 5th International 
Symposium on Landslides, vol. 1, "Landslides, Balkema, Rotterdam, 37-56.

Sassa, K. (1996), "Prediction of earthquake induced landslides", Landslides. Balkema, Rotterdam, 115-132.

Tang, C.L., Hu, J.C., Lin, M.L., Angelier, J., Liu, C.Y., Chan, Y.C. and Chu, H.T. (2009), "The Tsaoling landslide triggered by the Chi-Chi earthquake, Taiwan: Insights from a discrete element simulation", Eng. Geol., 106(1-2), 1-19.

Troncone, A. (2005), "Numerical analysis of a landslide in soils with strain-softening behavior", Geotechnique, 55(8), 585-596.

Vardoulakis, I. (2002), "Dynamic thermo-poro-mechanical analysis of catastrophic landslides", Geotechnique, 52(3), 157-171.

Wu, J.H., Lin, J.S. and Chen, C.S. (2008), "Dynamic discrete analysis of an earthquake-induced large-scale landslide", Int. J. Rock. Mech. Mining. Sci., 46(2), 397-407.

$\mathrm{Xu}, \mathrm{Q}$. and Huang, R.Q. (2008), "Kinetics characteristics of large landslides triggered by May 12th Wenchuan earthquake", J. Eng. Geol., 16(6), 721-729. (in Chinese)

Yin, Y.P. (2009), "Rapid and long run-out features of landslides triggered by the Wenchuan Earthquake", J. Eng. Geol., 17(2), 153-166. (in Chinese)

$C C$ 